\title{
Análise de crescimento em cultivares de alface nas condições do sul do Piauí
}

\author{
Alan Mario Zuffo ${ }^{1 *}$, Joacir Mario Zuffo Júnior ${ }^{2}$, Luana Maria Alves da Silva ${ }^{3}$, \\ Roberto Lustosa da Silva ${ }^{4}$ Karen Oliveira de Menezes ${ }^{3}$
}

10.1590/0034-737X201663020005

\section{RESUMO}

Objetivou-se, com este trabalho, avaliar o crescimento de quatro cultivares de alface, nas condições do sul do Piauí, para recomendar os melhores para a região. O experimento foi realizado em casa de vegetação, em blocos casualizados, com avaliação em parcelas subdivididas no tempo, avaliadas em seis épocas (20, 24, 28, 32, 36, 40 dias após a semeadura - DAS) e com os tratamentos correspondentes a quatro cultivares (Americana Rafaela ${ }^{\circledR}$, Grand Rapids TBR $^{\circledR}$, Crespa Repolhuda ${ }^{\circledR}$ e Repolhuda Todo ano ${ }^{\circledR}$ ), com cinco repetições. Foram avaliados área foliar, número de folhas, diâmetro de coleto, massa fresca da parte aérea, massa seca da parte aérea, de raízes e total e os índices físiológicos da análise de crescimento. Os cultivares de alface interferiram significativamente nos parâmetros estudados, sendo que Americana Rafaela ${ }^{\circledR}$ e Repolhuda todo ano ${ }^{\circledR}$, nas condições que foram submetidas, apresentaram melhores desempenhos e maiores índices morfofisiológicos, cultivados em vaso. Os cultivares Americana Rafaela ${ }^{\circledR}$ e Repolhuda todo ano ${ }^{\circledR}$ podem ser produzidos nas condições do sul do Piauí.

Palavras-chave: hortaliças, índices fisiológicos, Lactuca sativa L.

\section{ABSTRACT}

\section{Growth analysis in lettuce cultivars in Southern Piauí}

The aim of this study was to evaluate the growth and recommend the best one (s) of four lettuce cultivars in Southern Piaui. The experiment was carried out in a greenhouse with a randomized block design, with split-plot in time evaluation $\left(20,24,28,32,36,40\right.$ days after sowing - DAS), and the corresponding treatments to four cultivars (Americana Rafaela ${ }^{\circledR}$, Grand Rapids TBR ${ }^{\circledR}$, Crespa Repolhuda ${ }^{\circledR}$ and Repolhuda todo ano ${ }^{\circledR}$ ) with five replications. We evaluated leaf area; leaf number; stem diameter; shoot fresh mass; shoot, root and total dry mass and physiological indexes of growth analysis. The cultivars showed significant effect in the studied parameters. Under the submitted conditions, the Americana Rafaela ${ }^{\circledR}$ and Repolhuda todo ano ${ }^{\circledR}$ lettuce cultivars showed better performance and greater morphological and physiological indexes. The cultivars Americana Rafaela ${ }^{\circledR}$ and Repolhuda todo ano ${ }^{\circledR}$ can be grown under Southern Piaui conditions.

Key words: greenery, physiological indexes, Lactuca sativa L.

\footnotetext{
Submetido em 05/04/2014 e aprovado em 29/12/2015.

${ }^{1}$ Universidade Federal de Lavras, Lavras, Minas Gerais, Brasil. alan_zuffo@hotmail.com

${ }^{2}$ Universidade do Estado de Mato Grosso, Nova Xavantina, Mato Grosso, Brasil. joacir_zuffo@ hotmail.com

${ }^{3}$ Universidade Federal do Piauí, Bom Jesus, Piauí, Brasil. luanaalves.agro@gmail.com; kren.oliveira@hotmail.com

${ }^{4}$ Universidade Federal do Piauí, Bom Jesus, Piauí, Brasil. robertofolha2010@ hotmail.com

*Autor para correspondência: alan_zuffo@hotmail.com
} 


\section{INTRODUÇÃO}

A alface [Lactuca sativa L.] destaca-se entre as hortaliças folhosas mais consumidas no Brasil, por sua importância alimentar como fonte de vitaminas, sais minerais e fibras (Bezerra Neto et al., 2005a; Santi et al., 2010), sendo que o seu consumo dá-se na forma in natura e nos mais variados tipos de saladas.

Apesar da cultura da alface ser explorada em todo o território nacional, na região nordeste, a produção é baixa, se comparada com a de outras regiões de clima ameno, não atendendo à demanda interna, dados o crescente consumo da hortaliça e sua baixa produção (Queiroga et al. 2001). Dentre os fatores relacionados com os baixos rendimentos, destacam-se a falta de pesquisas sobre cultivares adaptados à região, bem como informações técnicas sobre o crescimento do vegetal, para melhor manejar a cultura nessas condições (Grangeiro et al., 2006).

O estudo da análise de crescimento é amplamente utilizado para acompanhar o padrão de crescimento da planta ou de partes dela, permitindo inferir a contribuição de diferentes processos fisiológicos para o crescimento vegetal, sendo útil no estudo de variações entre plantas geneticamente diferentes ou sob diferentes condições ambientais (Aguilera et al., 2004; Bragança et al., 2010 ). Este estudo baseia-se na produção fotossintética ao longo do desenvolvimento ontogenético da cultura, permitindo conhecer o acúmulo de matéria orgânica das plantas, sua distribuição e eficiência em ambiente natural ou controlado (Benincasa, 2003).

As relações entre as condições climáticas e a produção agrícola são complexas, pois afetam diretamente o crescimento e o desenvolvimento das plantas, sob diferentes formas, nos diversos estádios das culturas (Caron et al., 2007). Para Gomes et al. (2005), o cultivo da alface apresenta limitações, principalmente em virtude de sua sensibilidade às condições adversas de temperatura, umidade $\mathrm{e}$ chuva. Entre eles, a temperatura do ar é a principal variável que determina a taxa de crescimento da cultura, alterando o período total para o crescimento necessário para atingir o ponto de colheita (Beckmann-Cavalcante et al., 2009). Entretanto, o fotoperíodo também é um fator limitante, em relação ao qual a planta exige dias curtos, durante a fase vegetativa, e dias longos, para que ocorra o pendoamento; quando há associação entre dias longos e temperaturas elevadas, acelera ainda mais o pendoamento (Bezerra Neto et al., 2005b; Luz et al., 2009; Diamante et al., 2013).

As recomendações de cultivares têm sido realizadas pelas empresas produtoras de sementes, mas nem sempre esses materiais adaptam-se a uma ampla faixa de ambientes (Gualberto et al., 2002). A adaptação de um cultivar em ampla faixa de ambientes é considerada de interesse para o produtor, quando se propõe a incrementar cultivos
(Figueiredo et al., 2004). Dificuldades surgem quando diversos fatores ambientais afetam o crescimento e o desenvolvimento da cultura da alface. Sendo assim, foram conduzidos diversos estudos, para avaliar o desempenho de cultivares nas diferentes regiões do Brasil (Yuri et al., 2005; Santos et al., 2009; Blat et al., 2011, Guimarães et al., 2011; Santana et al., 2012; Azevedo et al., 2013), com resultados significativos.

O sul do Estado do Piauí, especificamente em Bom Jesus, é caracterizado por temperaturas altas, sendo média de $26,5^{\circ} \mathrm{C}$, embora, durante o ano, sejam comuns temperaturas próximas a $40^{\circ} \mathrm{C}$ (Viana et al., 2002). Considerandose que o maior desafio é selecionar cultivares que apresentem altas produtividades sob elevadas temperaturas, neste estudo, objetivou-se avaliar o crescimento de quatro cultivares de alface, nas condições do sul do Piauí, para recomendar os melhores para a região.

\section{MATERIAL E MÉTODOS}

O experimento foi realizado em casa de vegetação, coberta por tela de sombreamento, com $50 \%$ de interceptação de luz, no Campus da Universidade Federal do Piauí (UFPI), em Bom Jesus, PI (0904'28" de latitude Sul, 44²1'31" de longitude Oeste e com altitude média de $277 \mathrm{~m}$ ), de 13 de agosto a 22 de setembro de 2012.

O clima da região é do tipo Aw, segundo a classificação climática global de Köppen, com duas estações bem definidas, sendo uma seca, de maio a setembro, e outra, chuvosa, de outubro a abril. Os dados climáticos (Figura 1) foram coletados na estação meteorológica do Instituto Nacional de Meteorologia (INMET), localizada a aproximadamente 200 metros do local de condução do experimento, às 10, 12 e 15 horas, sendo calculados os valores médios entre os três períodos.

O solo utilizado no experimento foi identificado com Latossolo distrófico Amarelo, foi coletado na camada de 0-0,20 m. O solo apresentou a seguinte constituição granulométrica: 640, 80 e $280 \mathrm{~g} \mathrm{~kg}^{-1}$ de areia, silte e argila, respectivamente. A composição química está apresentada na Tabela 1.

O delineamento experimental utilizado foi em blocos casualizados, com avaliação feita em parcelas subdividas no tempo. Os tratamentos foram constituídos por quatro cultivares de alface (parcelas): Americana Rafaela ${ }^{\circledR}$, Grand Rapids TBR ${ }^{\circledR}$, Crespa Repolhuda ${ }^{\circledR}$ e Repolhuda Todo ano ${ }^{\circledR}$, avaliadas em seis épocas de amostragem para análise de crescimento da cultura (subparcelas): 20, 24, 28, 32, 36, 40 dias após a semeadura (DAS), perfazendo 24 tratamentos, com cinco repetições, sendo que cada tratamento foi constituído por três vasos com uma planta cada.

Os cultivares de alface foram semeados diretamente em vasos de polietileno rígido preto, preenchidos com 5 
$\mathrm{dm}^{3}$ de substrato, constituído pela mistura de solo (60\%), esterco bovino curtido (30\%) e casca de arroz carbonizada $(10 \%)$. A semeadura foi realizada com cinco sementes por vaso, com posterior desbaste, deixando apenas uma plântula por vaso. Durante a realização do experimento, foram feitas irrigações diárias para repor a água evapotranspirada e manter a capacidade de campo do solo. Foi reali- zada a correção do pH do solo para elevação da saturação por base a $80 \%$ (Comissão de Fertilidade do Solo do Estado de Minas Gerais, 1999).

Coletas sucessivas de três plantas por parcela foram realizadas a partir do vigésimo DAS, com intervalos regulares de quatro dias, até o ponto de colheita, que teve seu ciclo reduzido por causa das altas temperaturas e do fato
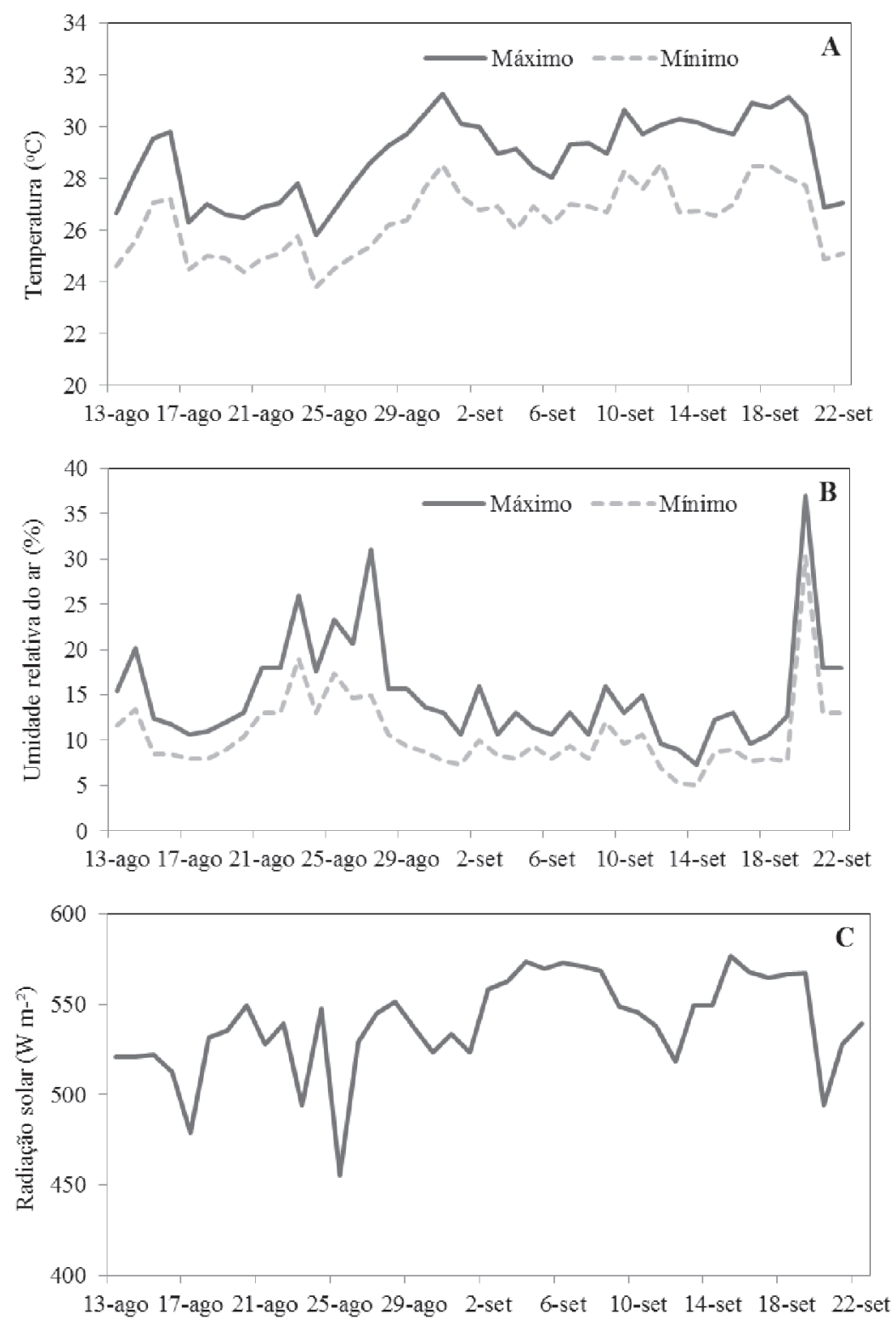

Figura 1: Valores médios da temperatura do ar, máxima e mínima (A); umidade relativa do ar, máxima e mínima (B); e, radiação solar (C) em Bom Jesus, PI, dados coletados às 10, 12 e 15 horas, entre 13 de agosto e 22 de setembro de 2012. Radiação solar média (W m²) corresponde a uma média das três horas de observação por dia (Estação meteorológica do INMET - estação de Bom Jesus, PI).

Tabela 1: Composição química do solo coletado na camada $(0-0,20 \mathrm{~m})$ da área experimental, antes da instalação do experimento, em Bom Jesus, PI, Brasil, 2012

\begin{tabular}{|c|c|c|c|c|c|c|c|c|c|c|}
\hline \multirow[t]{2}{*}{ pH CaCl${ }_{2}$} & $\mathrm{Ca}^{2+}$ & $\mathbf{M g}^{2+}$ & $\mathbf{A l}^{3+}$ & $\mathbf{H}^{+}+\mathrm{Al}^{3+}$ & SB & CTC & $\mathbf{P}$ & $\mathbf{K}$ & \multirow{2}{*}{$\begin{array}{c}\text { MO } \\
\mathrm{g} \mathrm{kg}^{-1}\end{array}$} & \multirow{2}{*}{$\begin{array}{c}\mathrm{V} \\
\%\end{array}$} \\
\hline & \multicolumn{6}{|c|}{$\mathrm{cmol}_{\mathrm{c}} \mathrm{dm}^{-3}$} & \multicolumn{2}{|c|}{$\mathrm{mg} \mathrm{dm}^{-3}$} & & \\
\hline 4,60 & 2,10 & 1,00 & 1,10 & 3,10 & 2,80 & 6,39 & 47,00 & 74,00 & 15,00 & 51,49 \\
\hline
\end{tabular}

H + Al: acidez potencial; SB: soma de bases; CTC: capacidade de troca catiônica a pH 7,0; MO: matéria orgânica; V: saturação por bases. 
de a semeadura ter sido realizada diretamente no local de crescimento, com ausência de transplante. Em cada coleta, foram avaliadas as seguintes variáveis: área foliar (AF) $\left(\mathrm{cm}^{2}\right)$ : pelo medidor de área foliar eletrônico (Li-Cor, L1$3100^{\circledR}$ ); número de folhas (NF) (unidade); diâmetro do coleto (DC) (mm): mensurado na altura do colo da planta superfície do solo por meio de leituras em paquímetro digital Clarke ${ }^{\circledR}$; massa fresca da parte aérea (MFPA), massas secas da parte aérea (MSPA), radicular (MSR) e total (MST) (g): material submetido à secagem em estufa com circulação forçada de ar, à temperatura de $60{ }^{\circ} \mathrm{C}$, por 72 horas, pesado em balança digital (precisão $0,01 \mathrm{~g}$ ).

Com esses dados, foram calculados os índices fisiológicos da análise de crescimento, de acordo com Benincasa (2003). Foram determinadas, para cada avaliação, a taxa de crescimento absoluto (TCA), a taxa de crescimento relativo (TCR), a taxa de assimilação líquida (TAL), a razão de área foliar (RAF), a razão de peso da folha (RPF), e a taxa de crescimento relativo da área foliar (TCR-AF).

A TCA, em g d ${ }^{-1}$, é calculada pela fórmula $\mathrm{TCA}=\left(\mathrm{MST}_{2}{ }_{-}\right.$ $\left.\mathrm{MST}_{1}\right) /\left(\mathrm{T}_{2}-\mathrm{T}_{1}\right)$, em que $\mathrm{MST}_{2}$ é a massa seca total da parte aérea atual $(\mathrm{g}) ; \mathrm{MST}_{1}$ é a massa seca total da parte aérea inicial $(\mathrm{g}) ; \mathrm{t}_{2}-\mathrm{t}_{1}$ é o intervalo de tempo entre duas coletas (4 dias). A taxa de TCR, em $\mathrm{g} \mathrm{g}^{-1}$ por d $\mathrm{d}^{-1}$, é calculada pela fórmula $\mathrm{TCR}=\left(\ln \mathrm{MST}_{2}-\ln \mathrm{MST}_{1}\right) /\left(\mathrm{T}_{2}-\mathrm{T}_{1}\right)$, sendo que, ln é o logaritmo Neperiano. A TAL é calculada pela fórmula TAL $=\left[\left(\mathrm{MST}_{2}-\mathrm{MST}_{1}\right) /\left(\mathrm{T}_{2}-\mathrm{T}_{1}\right),\right] \cdot\left[\left(\ln \mathrm{AF}_{2}-\ln \right.\right.$ $\left.\mathrm{AF}_{1}\right) /\left(\mathrm{AF}_{2}-\mathrm{AF}_{1}\right]$, em que $\mathrm{AF}_{2}$ e $\mathrm{AF}_{1}$ corresponde a área foliar total atual da parte aérea $\left(\mathrm{cm}^{2}\right)$ nos tempos $\mathrm{T}_{2} \mathrm{e} \mathrm{T}_{1}$, respectivamente. A RAF, em $\mathrm{cm}^{2} \mathrm{~g}^{-1}$ é calculada pela fórmula $\mathrm{RAF}=\mathrm{AF} / \mathrm{MST}$, sendo que AF é a área foliar atual $\left(\mathrm{cm}^{2}\right)$; MST é a massa seca total atual (g). A RPF é calculada pela fórmula RPF $=$ MSF/MST, sendo que MSF é a matéria seca das folhas ( $\mathrm{g}$ ) e MST é a massa seca total atual (g), seu valor expresso em $\mathrm{g} \mathrm{d}^{-1}$. $\mathrm{ATCR}_{\mathrm{AF}}, \mathrm{em} \mathrm{cm}^{2} \mathrm{~cm}^{-2}$ $\mathrm{d}^{-1}$, é calculada pela fórmula $\mathrm{TCR}_{\mathrm{AF}}=\left(\ln \mathrm{AF}_{2}-\ln \mathrm{AF}_{1}\right) /\left(\mathrm{T}_{2}\right.$ - $\mathrm{T}_{1}$ ), em que $\mathrm{AF}_{2}$ é a área foliar total atual da parte aérea $\left(\mathrm{cm}^{2}\right)$ e $\ln$ é o logaritmo Neperiano.

A comparação entre as médias para as fontes de variações e suas interações foi realizada pelo teste de Tukey, a $5 \%$ de probabilidade, utilizando-se o programa estatístico Sisvar $^{\circledR}$ (Ferreira, 2011). As variáveis estudadas ao longo do ciclo de cultivo foram analisados por regressão polinomial, em que as equações foram ajustadas, utilizando-se os parâmetros de correlação e de determinação para as variáveis avaliadas, em função das épocas de desenvolvimento da cultura e dos cultivares de alface, empregando-se o programa estatístico SigmaPlot ${ }^{\circledR}$. Quanto aos parâmetros fisiológicos calculados na análise de crescimento, não foram realizadas análises de variância. Segundo Banzatto \& Kronka (1989), não se pode afirmar que variáveis calculadas obedeçam às pressuposições básicas para esse tipo de análise.

\section{RESULTADOS E DISCUSSÃO}

Na Tabela 2, é apresentado o resumo da análise de variância (valores de F) das características AF, NF, DC, MFPA, MSPA, MSR, MST de cultivares de alface em função das épocas de avaliação. De maneira geral, verificouse que os parâmetros avaliados foram significativamente ( $\mathrm{p}<0,01)$ influenciados pelos cultivares e pelas épocas de avaliação (Tabela 2). Também é possível verificar interações significativas $(\mathrm{p}<0,01)$ entre os fatores estudados, indicando que há interdependência entre eles.

Comparando-se os resultados dos parâmetros avaliados (AF, NF, DC, MFPA, MSPA, MSR e MST), verifica-se que as alfaces Americana Rafaela ${ }^{\circledR}$ e Repolhuda todo ano ${ }^{\circledR}$ não diferiram entre si, sendo superiores aos demais cultivares, Grand Rapids TBR ${ }^{\circledR}$ e Crespa Repolhuda ${ }^{\circledR}$ (Tabela 2). Isso pode estar relacionado com o melhoramento genético da cultura, que tornou alguns cultivares mais tolerantes a altas temperaturas, conforme documentado por Feltrim et al. (2005).

Por meio da distribuição de AF nas diferentes épocas (Figura 2A), verificou-se que o crescimento da AF foi lento, até $28 \mathrm{DAS}$, para todos os cultivares, em comparação com a AF final aos $40 \mathrm{DAS}$, fato comum em hortaliças que estão em estádios de crescimento e desenvolvimento. Também é possível observar que a partir dos 28 DAS, os cultivares de Americana Rafaela ${ }^{\circledR}$ e Repolhuda Todo ano ${ }^{\circledR}$ apresentaram maiores valores de AF.

De maneira geral, todos os parâmetros ajustaram-se de forma quadrática com elevado coeficiente de determinação (Figura 2F). Observaram-se os valores máximos de número de folhas (NF) e de diâmetro do coleto (DC) de 27 unidades e de $14,47 \mathrm{~mm}$, respectivamente, para o cultivar Repolhuda todo ano ${ }^{\circledR}$ (Figuras 2B e 2C).

Com exceção do NF e do DC, que apresentaram comportamento linear (Figuras 2B e 2C), os demais parâmetros apresentaram os maiores acúmulos de massa para o cultivar Americana Rafaela ${ }^{\circledR}$, sendo que o crescimento foi lento até aos 28 DAS. A maior MFPA foi observada no cultivar Americana Rafaela ${ }^{\circledR}$ (Figura 2D), com expressivo crescimento após os 28 DAS até o final do ciclo de cultivo (40 DAS), atingindo 146,$70 ; 89,45 ; 81,35$; e 64,34 g g $^{-1}$, respectivamente, para os cultivares Americana Rafaela ${ }^{\circledR}$, Crespa Repolhuda $^{\circledR}$; Repolhuda todo ano ${ }^{\circledR}$, Grand Rapids TBR ${ }^{\circledR}$ (Figura 2D). Dessa forma, vê-se que a alface segue a tendência de crescente produção de AF e de massa ao longo da sua ontogenia, conforme observado também para a cultura do rabanete (Pisco \& Arenas, 2006; Pédo et al., 2010).

A maior acumulação de MSPA e MST (Figura 2E e $2 \mathrm{G})$ no cultivar Americana Rafaela ${ }^{\circledR}$ é o reflexo da maior AF, pois o valor dessa variável está associado diretamente ao da área fotossintética da planta. Plantas com 
maior área fotossintética, consequentemente, terão maior produção de fotoassimilados, resultando em crescimento e desenvolvimento. Guimarães et al. (2011), ao trabalhar com 20 acessos de alface para produção orgânica em vasos, obtiveram resultados de produção de massa seca da parte aérea semelhantes aos obtidos neste experimento.

A massa seca das plantas está diretamente associada à capacidade de fixação de $\mathrm{CO}_{2}$ atmosférico, por fotossíntese, e esta é tanto mais elevada quanto maior for a AF. Entretanto, o ganho de massa não pode ser atribuído apenas à AF, mas também à capacidade de aproveitamento da energia luminosa, que envolve, sobretudo o mecanismo de fixação de carbono, que é o responsável principal por governar o crescimento e o desenvolvimento vegetal (Caron et al., 2012).

O desenvolvimento da alface é bastante influenciado pelas condições ambientais (Yuri et al., 2002), dentre as quais se destaca a temperatura do ar. Segundo Taiz e Zeiger (2009), a temperatura afeta a velocidade das reações químicas e dos processos internos de transporte dos solutos e o desenvolvimento normal das plantas.

Durante a condução do experimento, as temperaturas médias, mínima e máxima registradas foram, respectivamente, 23,80 e $31,27^{\circ} \mathrm{C}$, valores superiores aos considerados ideais para a cultura $\left[15\right.$ e $24{ }^{\circ} \mathrm{C}$ (Knott, 1962), 7 a $27^{\circ} \mathrm{C}$ (Puiatti \& Finger, 2005), 20 e $25^{\circ} \mathrm{C}$ (Embrapa, 2003)]. Esses valores permitem afirmar que a temperatura influenciou negativamente a AF, DC, NF, MFPA, MSPA, MSR, MST. Esses resultados corroboram os encontrados por Santos et al. (2009), ao verificarem que os cultivares de alface expostos a altas temperaturas do ar, com médias mínima e máxima de 20,3 e $35,3^{\circ} \mathrm{C}$, respectivamente, apresentaram reduções significativas da MST, variando de 52,5 a 111,5 g planta ${ }^{-1}$.
Adicionalmente, durante a condução do experimento, verificaram-se valores de umidade relativa do ar (UR) abaixo dos considerados ideais para o cultivo da alface. Cermeñozs (1990) relata que os valores UR ideais para o cultivo da alface variam de 60 a $80 \%$.

A TCA é a variação ou o incremento de crescimento entre duas amostragens, ao longo do período (Benincasa, 2003). Verifica-se, na Figura 3A, que há um crescimento vegetativo acelerado dos 36 aos $40 \mathrm{DAE}$, na ordem dos cultivares Americana Rafaela ${ }^{\circledR}>$ Repolhuda todo ano ${ }^{\circledR}$ $>$ Crespa Repolhuda ${ }^{\circledR}>$ Grand Rapids TBR $^{\circledR}$, o que pode estar relacionado com as características intrínsecas dos cultivares.

A TCR representa o incremento da matéria seca já existente por unidade de matéria seca existente em um determinado período (Benincasa, 2003). Observou-se que Americana Rafaela ${ }^{\circledR}$ apresentou maior TCR aos 20 DAS (Figura 3B). Nesse período, verificou-se o máximo acúmulo da TCR pelos cultivares Americana Rafaela $^{\circledR}$, Repolhuda Todo ano ${ }^{\circledR}$, Grand Rapids TBR ${ }^{\circledR}$, Crespa Repolhuda ${ }^{\circledR}$, com as taxas de 3,06; 2,94; 2,83; 2,68 $\mathrm{g} \mathrm{g}^{-1} \mathrm{~d}^{-1}$, respectivamente. Posteriormente, aos 20 DAS, de maneira geral, independentemente dos cultivares, observou-se brusca redução, até 32 DAS, estabilizando-se, após esse período, até o final do ciclo da cultura. O cultivar Americana Rafaela ${ }^{\circledR}$ mostrou eficiência de conversão de massa seca maior que a dos demais cultivares em todas as épocas avaliadas. Provavelmente, a redução foi provocada pelo aumento da atividade respiratória e pelo autossombreamento, que aumenta de acordo com a idade da planta (Milthorpe \& Moorby, 1974), sendo que, no final do ciclo, o crescimento pode-se tornar negativo, por morte de órgãos vegetais como folhas e gemas (Beckmann-Cavalcante et al., 2009).

A TAL reflete a eficiência fotossintética das folhas (Benincasa, 2003). Verifica-se, na Figura 3C, que os cultiva-

Tabela 2: Valores de F para área foliar (AF), número de folhas (NF), diâmetro de coleto (DC), massa fresca da parte aérea (MFPA), massa seca da parte aérea (MSPA), massa seca das raízes (MSR), massa seca total (MST) de cultivares de alface [Lactuca sativa L.] cultivado em vaso, em função de cultivares e de épocas de avaliação. Bom Jesus,PI, Brasil, 2012

\begin{tabular}{|c|c|c|c|c|c|c|c|}
\hline \multirow{2}{*}{ Fontes de Variação } & \multirow{2}{*}{$\begin{array}{c}\mathbf{A F} \\
\left(\mathrm{cm}^{2}\right)\end{array}$} & \multirow{2}{*}{$\begin{array}{c}\mathrm{NF} \\
\text { (unidades) }\end{array}$} & \multirow{2}{*}{$\begin{array}{c}\text { DC } \\
(\mathbf{m m})\end{array}$} & MFPA & MSPA & MSR & MST \\
\hline & & & & \multicolumn{4}{|c|}{ (g) } \\
\hline Cultivares (C) & $157,24 * *$ & $79,74 * *$ & $17,76 * *$ & $94,00 * *$ & $29,45 * *$ & $25,55 * *$ & $30,57 * *$ \\
\hline Crespa Repolhuda ${ }^{\circledR}$ & 495,35 B & $8,58 \mathrm{C}$ & $5,84 \mathrm{~B}$ & $27,75 \mathrm{~B}$ & $1,52 \mathrm{~B}$ & $0,09 \mathrm{~B}$ & $1,62 \mathrm{~B}$ \\
\hline Grand Rapids TBR ${ }^{\circledR}$ & $412,33 \mathrm{C}$ & $8,95 \mathrm{C}$ & $6,04 \mathrm{~B}$ & $22,44 \mathrm{C}$ & $1,23 \mathrm{C}$ & $0,08 \mathrm{~B}$ & $1,32 \mathrm{C}$ \\
\hline Americana Rafaela ${ }^{\circledR}$ & $829,59 \mathrm{~A}$ & $12,87 \mathrm{~A}$ & $6,88 \mathrm{~A}$ & $42,27 \mathrm{~A}$ & $2,16 \mathrm{~A}$ & $0,11 \mathrm{~A}$ & $2,28 \mathrm{~A}$ \\
\hline Repolhuda Todo ano ${ }^{\circledR}$ & $774,32 \mathrm{~A}$ & $14,25 \mathrm{~A}$ & 7,22 A & $38,42 \mathrm{~A}$ & $1,97 \mathrm{~A}$ & $0,12 \mathrm{~A}$ & $2,09 \mathrm{~A}$ \\
\hline Época $(E)$ & $1028,29 * *$ & $438,04 * *$ & $362,12 * *$ & $1439,95 * *$ & $486,49 * *$ & $463,12 * *$ & $531,11 * *$ \\
\hline $\mathrm{C} \times \mathrm{E}$ & $48,81 * *$ & $15,49 * *$ & $10,50 * *$ & $52,43 * *$ & $12,38 * *$ & $8,98 * *$ & $12,98 * *$ \\
\hline Bloco & 0,20 & 1,11 & 0,64 & 1,30 & 0,39 & 2,53 & 1,22 \\
\hline$\overline{\mathrm{CV} 1(\%)}$ & 12,76 & 13,48 & 11,81 & 14,16 & 22,05 & 17,61 & 21,25 \\
\hline CV $2(\%)$ & 15,08 & 10,58 & 12,12 & 12,92 & 21,80 & 23,79 & 20,94 \\
\hline
\end{tabular}

** significativo a $1 \%$ de probabilidade; as médias seguidas pela mesma letra, em cada coluna, não são diferentes estatisticamente pelo teste de Tukey a $5 \%$. CV= coeficiente de variação. 
A OAlface Crespa Repolhuda $=12,167 \mathrm{x}^{2}-600,23 \mathrm{x}+7318,5\left(\mathrm{R}^{2}=0,96 * *\right)$

Alface Grand Rapids TBR $=7,1503 \mathrm{x}^{2}-318,32 \mathrm{x}+3555\left(\mathrm{R}^{2}=0,97^{* *}\right)$

3500 A Alface Americana Rafaela $=5,6126 \mathrm{x}^{2}-264,42 \mathrm{x}+3114,5\left(\mathrm{R}^{2}=0,98^{* *}\right)$

DAlface Repolhuda todo $a n 0=3,0014 \mathrm{x}^{2}-124,15 \mathrm{x}+1295,5\left(\mathrm{R}^{2}=0,97 * *\right)$

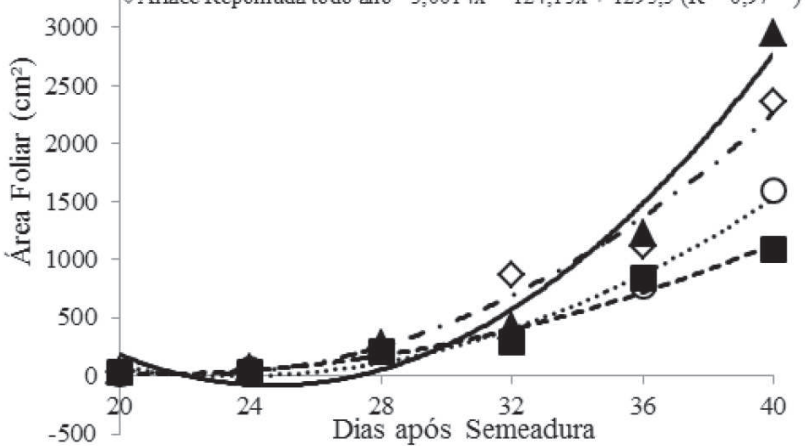

C 18 OAlface Crespa Repolhuda $=0,0077 \mathrm{x}^{2}-0,0297 \mathrm{x}-0,5657\left(\mathrm{R}^{2}=0,97 * *\right)$ -Alface Grand Rapids TBR $=-0,0051 \mathrm{x}^{2}-0,6798 \mathrm{x}-9,4929\left(\mathrm{R}^{2}=0,99 * *\right)$

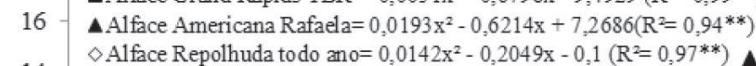

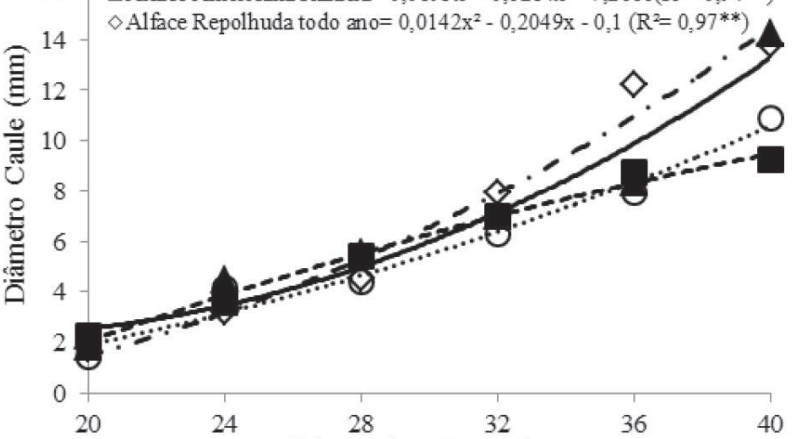

Dias após a Semeadura

E OAlface Crespa Repolhuda $=0,0169 \mathrm{x}^{2}-0,6823 \mathrm{x}+6,8076\left(\mathrm{R}^{2}=0,99 * *\right)$ - Alface Grand Rapids TBR $=0,009 \mathrm{x}^{2}-0,346 \mathrm{x}+3,127\left(\mathrm{R}^{2}=0,99 * *\right)$

8
$7 . \quad \Delta$ Alface Americana Rafaela $=0,0259 \mathrm{x}^{2}-1,0651 \mathrm{x}+10,841\left(\mathrm{R}^{2}=0,97^{* *}\right)$

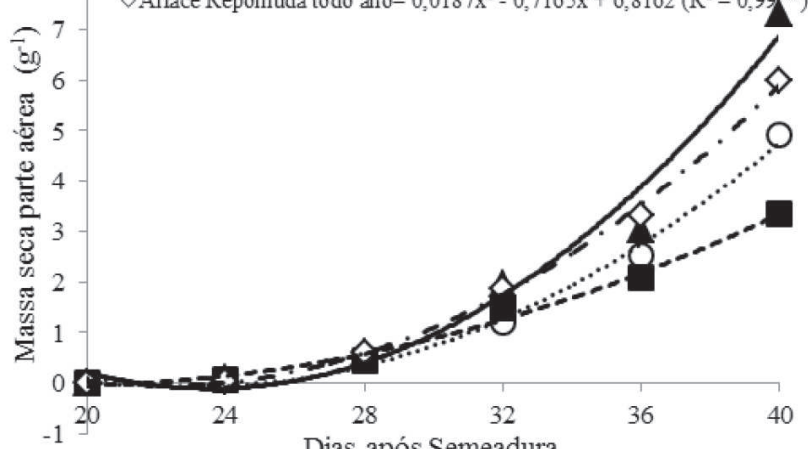

$-120$

Dias após Semeadura

G Alface Crespa Repolhuda $=0,0187 \mathrm{x}^{2}-0,8734 \mathrm{x}+10,114\left(\mathrm{R}^{2}=0,99^{* *}\right)$.

$\Delta$ Alface Americana Rafaela $=0,0274 \mathrm{x}^{2}-1,2944 \mathrm{x}+15,149\left(\mathrm{R}^{2}=0,97^{* *}\right)$

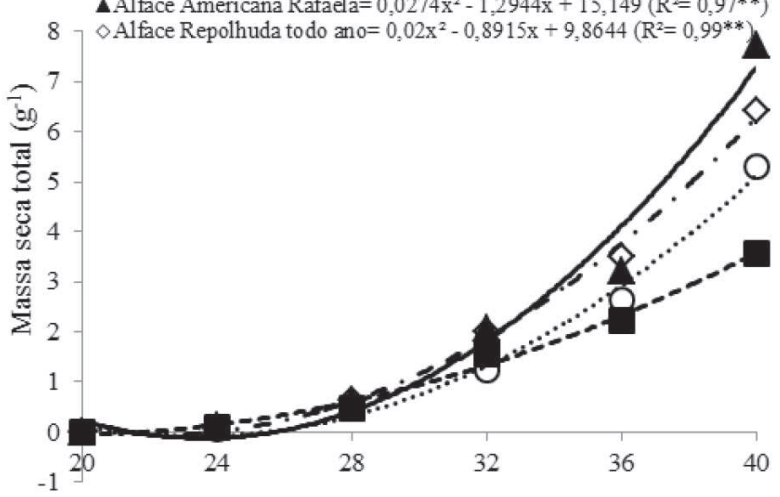

B 35 OAlface Crespa Repolhuda $=-0,0064 \mathrm{x}^{2}-0,935 \mathrm{x}-13,393\left(\mathrm{R}^{2}=0,96^{* *}\right)$

-Alface Grand Rapids TBR $=0,002 \mathrm{x}^{2}+0,5239 \mathrm{x}-8,6071\left(\mathrm{R}^{2}=0,98 * *\right)$

$\Delta$ Alface Americana Rafaela $=0,0025 \mathrm{x}^{2}+0,569 \mathrm{x}-9,0714\left(\mathrm{R}^{2}=0,98 * *\right)$

$\diamond$ Alface Repolhuda todo ano $=0,0142 \mathrm{x}^{2}+0,3283 \mathrm{x}-9,0714\left(\mathrm{R}^{2}=0,98 * *\right)$

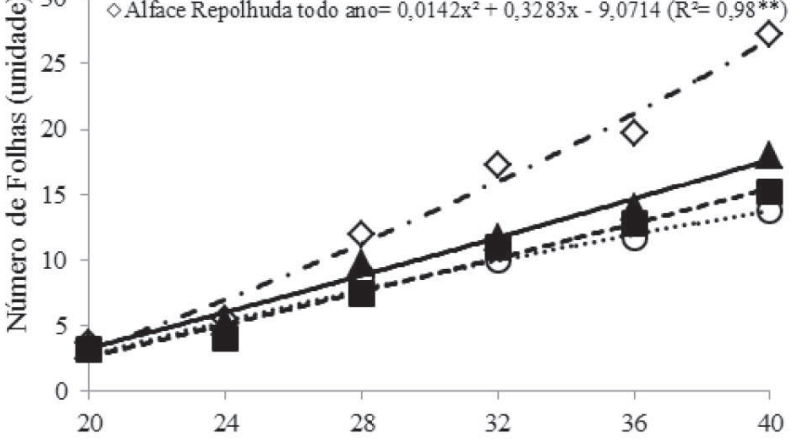

D Alface Crespa Repolhuda $=0,2428 \mathrm{x}^{2}-8,8877 \mathrm{x}+80,078\left(\mathrm{R}^{2}=0,99^{* *}\right)$ - Alface Grand Rapids TBR $=0,1741 \mathrm{x}^{2}-6,2267 \mathrm{x}+55,548\left(\mathrm{R}^{2}=0,98^{* *}\right)$ $\Delta$ Alface Americana Rafaela $=0,5497 \mathrm{x}^{2}-23,105 \mathrm{x}+239,68\left(\mathrm{R}^{2}=0,96 * *\right)$

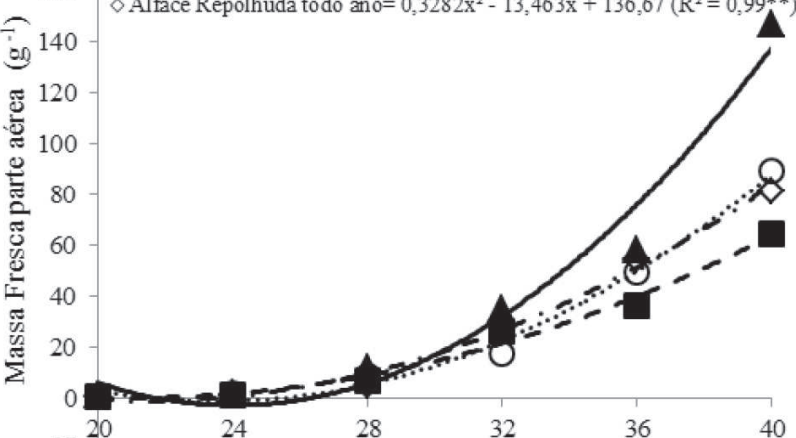

$\diamond$ Alface Repolhuda todo an $0=0,3282 x^{2}-13,463 x+136,67\left(R^{2}=0,99 * *\right.$

2020

F OAlface Cresp a Repolhuda $=0,0018 \mathrm{x}^{2}-0,0895 \mathrm{x}+1,1066\left(\mathrm{R}^{2}=0,94 * *\right)$ Alface Grand Rapids TBR $=0.0006 \mathrm{x}^{2}-0,0222 \mathrm{x}+0.2192\left(\mathrm{R}^{2}=0.99^{* *}\right)$ $0,45 \Delta$ Alface Americana Rafaela $=0,0015 \mathrm{x}^{2}-0,074 \mathrm{x}+0,8797\left(\mathrm{R}^{2}=0,98^{* *}\right)$ $0,40-\diamond$ Alface Repolhuda todo ano $=0,0014 \mathrm{x}^{2}-0,0629 \mathrm{x}+0,7306\left(\mathrm{R}^{2}=0,94\right.$ * $)$

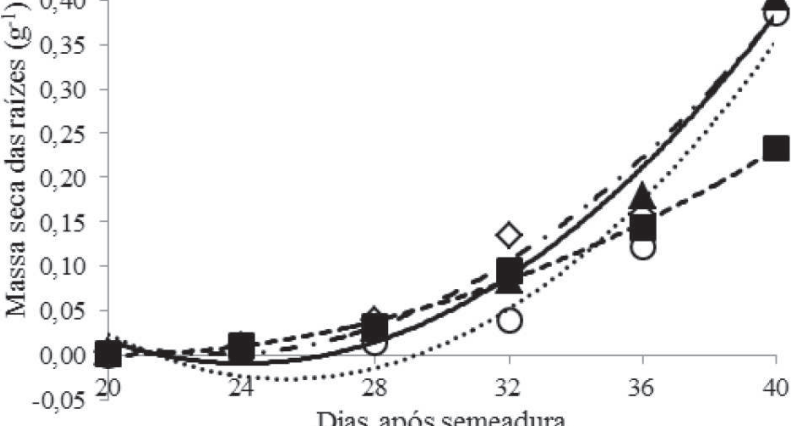
Dias após semeadura

Figura 2: Área foliar (A), número de folhas (B), diâmetro do coleto (C), massa fresca da parte aérea (D), massa seca da parte aérea (E), massa seca das raízes (F) e massa seca total $(\mathrm{G})$ de plantas de alface [Lactuca sativa L.] cultivada em vaso, em função de cultivares e épocas de avaliação. Bom Jesus, PI, 2012.

Rev. Ceres, Viçosa, v. 63, n.2, p. 145-153, mar/abr, 2016 
res Repolhuda todo ano ${ }^{\circledR}$ e Grand Rapids $\mathrm{TBR}^{\circledR}$ apresentaram a maior TAL aos 24 DAS, com as taxas de 4,84; 4,40 mg $\mathrm{cm}^{-2} \mathrm{~d}^{-1}$, respectivamente. Posteriormente, aos $24 \mathrm{DAS}$, de maneira geral, independentemente dos cultivares, observou-se brusca redução até 32 DAS, estabilizando-se, após esse período, até o final do ciclo da cultura.
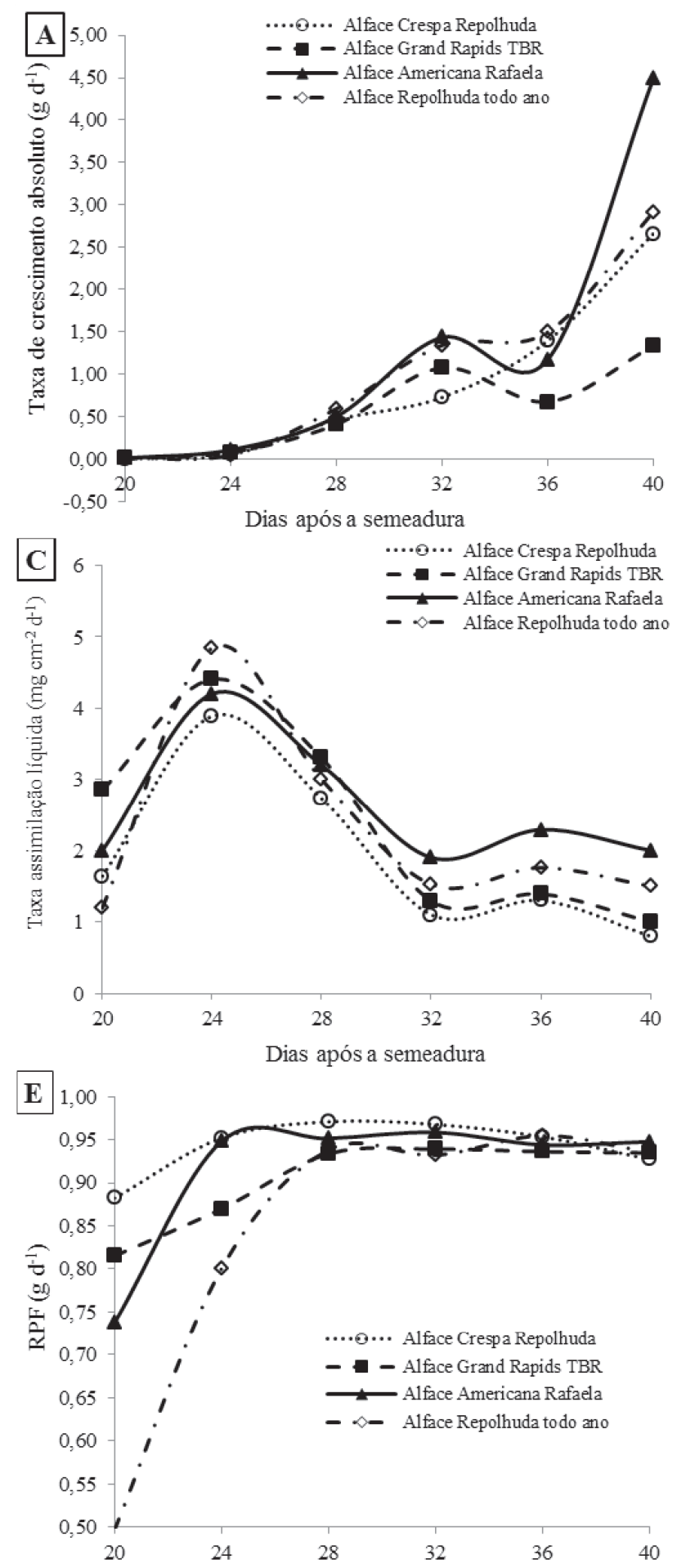

A redução da TALé consequência da taxa fotossintética, da dimensão foliar, da duração do período vegetativo, da distribuição das folhas no dossel, do ângulo foliar e da distribuição de assimilados (Pedó et al., 2010). Para Milthorpe \& Moorby (1974), o declínio é devido ao efeito do sombreamento das folhas inferiores. Sendo assim, a
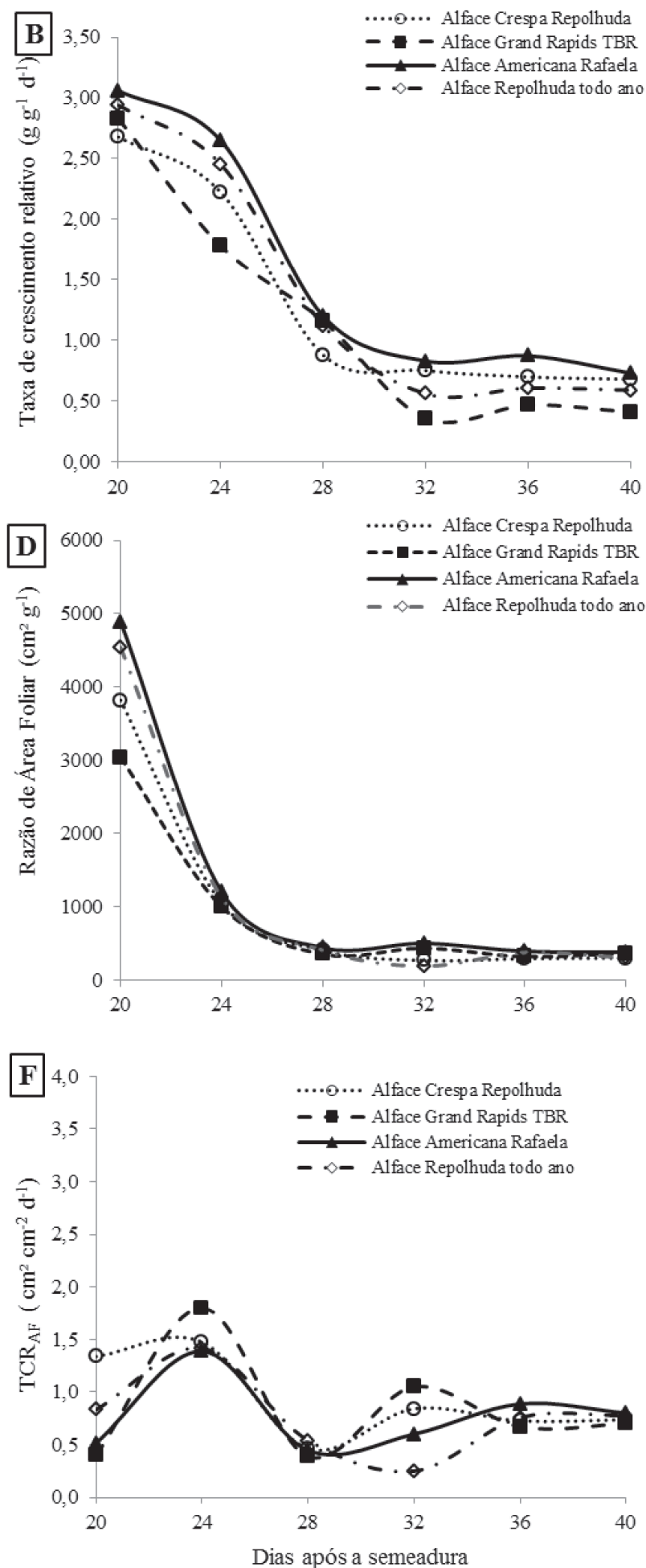

Figura 3: Taxa de crescimento absoluto (A), taxa de crescimento relativo (B), taxa de assimilação líquida (C), razão de área foliar (D), razão de peso de folha (E) e taxa de crescimento relativo da área foliar (F) de plantas de Alface (Lactuca sativa L.), cultivadas em vaso, em função de cultivares e de épocas de avaliação. Bom Jesus, PI, 2012. 
TCA tende a ser maior nos estádios iniciais, por causa do menor autossombreamento (Gondim et al., 2008). Assim, a TAL tende a ser maior no início do ciclo, quando o autossombreamento é reduzido (Gondim et al., 2008). Seu decréscimo é esperado à medida que a área foliar útil à fotossíntese é reduzida (Conceição et al., 2005). Esses resultados assemelham aos de Pedó et al. (2010), que observaram a redução da TAL, em cultivares de rabanete, ao aumentar a AF, por maior autossombreamento das folhas inferiores.

A RAF, em função do tempo, foi maior aos 20 DAS e mostrou declínio acentuado após esse período até 24 DAS, estabilizando-se até a colheita (Figura 3D). Para Caron et al. (2007), isso indica que, nesse estádio, a maior parte do material fotossintetizado é acumulada na fitomassa aérea da alface, para maior captação da radiação solar disponível. A partir desse período ocorreram decréscimos subsequentes do desenvolvimento fenológico da cultura, decorrentes do surgimento de tecidos e estruturas não assimilatórias, como flores e sementes, além do autossombreamento, secamento e queda de folhas, com a idade da planta.

Os maiores valor da RAF correspondem aos dos cultivares Americana Rafaela ${ }^{\circledR}$ e Repolhuda todo ano ${ }^{\circledR}$, independentemente da época avaliada, fato comprovado por terem apresentado maiores MSPA, MST, e AF. Apesar de ambos os cultivares não apresentarem diferença estatística, as curvas de ambos se igualam a partir dos 24 DAS. O menor RAF do cultivar Repolhuda todo ano ${ }^{\circledR}$ pode ser devido a suas características intrínsecas, que lhe conferem maior eficiência das folhas para realizar a fotossíntese e produzir fitomassa. Para Benincasa (2003), a RAF expressa à área foliar útil para fotossíntese, a razão entre a área foliar e a massa seca total. Segundo o autor, o declínio da RAF ocorre, pelo aumento da interferência de folhas superiores sobre as inferiores, à medida que a planta cresce, sendo uma tendência da AF útil diminuir de acordo com o estádio de desenvolvimento da planta. Esses resultados corroboram os obtidos por Beckmann-Cavalcante et al. (2009), em experimentos com o desenvolvimento de crisântemo com soluções nutritivas.

A RPF apresentou maiores valores para o cultivar Crespa Repolhuda ${ }^{\circledR}$ (Figura 3E). Por se tratar de uma variável que corresponde à quantidade de matéria seca armazenada nas folhas e da massa seca retida em toda a planta (Benincasa, 2003), é possível inferir que o cultivar Crespa Repolhuda ${ }^{\circledR}$ tem maior RPF, à medida que cresce, por causa da menor quantidade de massa que é retida nas folhas, tendo uma maior exportação para os demais drenos da planta. Já para a $\mathrm{TCR}_{\mathrm{AF}}$ verificou-se que, nas primeiras semanas, os cultivares apresentaram um impulso no crescimento, com maiores valores, sendo que, a partir dos 32 DAS, o cultivar Americana Rafaela ${ }^{\circledR}$ foi o melhor.
De maneira geral, verifica-se que os melhores crescimentos referem-se aos cultivares de alface Americana Rafaela ${ }^{\circledR} \mathrm{e}$ Repolhuda todo ano ${ }^{\circledR}$, por apresentarem maiores AF, DC, NF, MFPA, MSPA, MSR, MST e, na análise de crescimento, de TCA, TCR, TAL, RAF e TCR ${ }_{\mathrm{AF}}$.

\section{CONCLUSÕES}

Os cultivares de alface Americana Rafaela ${ }^{\circledR}$ e Repolhuda todo ano ${ }^{\circledR}$ são mais eficientes que Grand Rapids TBR ${ }^{\circledR} \mathrm{e}$ Crespa Repolhuda ${ }^{\circledR}$, nas condições do sul do Piauí, por apresentarem melhor desempenho e maiores índices morfofisiológicos para a cultura da alface, cultivados em vaso.

\section{AGRADECIMENTOS}

Os autores expressam seus agradecimentos ao $\mathrm{CNPq}$ (Conselho Nacional de Desenvolvimento Científico e Tecnológico) e à CAPES (Coordenação de Aperfeiçoamento de Pessoal de Nível Superior), pela concessão de bolsas de Doutorado e Mestrado, e a Universidade Federal do Piauí e a Universidade Federal de Lavras, pelo apoio logístico.

\section{REFERÊNCIAS}

Aguilera DB, Ferreira FA \& Cecon PR (2004) Crescimento de Siegesbeckia orientalis sob diferentes condições de luminosidade. Planta daninha, 22:43-51.

Azevedo AM, Andrade Júnior VC, Oliveira CM, Fernandes JSC, Pedrosa CE, Dornas MFS \& Castro BMC (2013) Seleção de genótipos de alface para cultivo protegido: divergência genética e importância de caracteres. Horticultura Brasileira, 31:260265

Banzatto DA \& Kronka SN (1989) Experimentação agrícola. Jaboticabal, UNESP. 247p.

Beckmann-Cavalcante MZ, Pivetta KFL, Cavalcante ÍHL, Cavalcante LF \& Bellingieri PA (2009) Soluções nutritivas no desenvolvimento do Crisântemo cultivado em vaso. Irriga, 14:205-219.

Benincasa MMP (2003) Análise de crescimento de plantas (noções básicas). Jaboticabal, FUNEP. 41p.

Bezerra Neto F, Rocha RHC, Rocha RC, Negreiros MZ, Leitão MMVBR, Nunes GHS, Sobrinho JE \& Queiroga RCF (2005a) Sombreamento para produção de mudas de alface em alta temperatura e ampla luminosidade. Horticultura Brasileira, 23:133137.

Bezerra Neto F, Carlos Rocha RC, Negreiros MZ, Rocha RHC \& Queiroga RCF (2005b) Produtividade de alface em função de condições de sombreamento e temperatura e luminosidade elevadas. Horticultura Brasileira, 23:189-192.

Blat SF, Branco RBF \& Trani PE (2011) Desempenho de cultivares de alface em Ribeirão Preto (SP) no cultivo de primavera. Pesquisa \& Tecnologia, 8:1-9.

Bragança SM, Martinez HEP, Leite HG, Santos LP, Lani JA, Sediyama CS \& Alvarez VVH (2010) Acumulação de matéria seca pelo cafeeiro conilon. Revista Ceres, 57:48-52. 
Caron BO, Manfron PA, Lúcio AD, Schmidt S, Medeiros SLP, Bonnecarrére RAG \& Neto DD (2007) Equações de estimativa da fitomassa da parte aérea da alface. Ciência Rural, 37:1248:1254.

Caron BO, Souza VQ, Trevisan R, Behling A, Schmidt D, Bamberg R \& Eloy E (2012) Eficiência de conversão da radiação fotossinteticamente ativa interceptada em fitomassa de mudas de eucalipto. Revista Árvore, 36:833-842.

Cermeñozs (1990) Estufas, instalações e manejo. Lisboa, Litexa Editora. 355p.

Comissão de Fertilidade do Solo do Estado de Minas Gerais (1999) Recomendações para o uso de corretivos e fertilizantes em Minas Gerais: $5^{\text {a }}$ aproximação. Viçosa, MG. 359p.

Conceição MK, Lopes NF \& Fortes GRL (2005) Análise de crescimento de plantas de batata-doce [Ipomoea batatas (L.) Lam] cultivares abóbora e da costa. Revista Brasileira de Agrociência, 11:273-278.

Diamante MS, Seabra Júnior S, Inagaki AM \& Silva RD (2013) Produção e resistência ao pendoamento de alfaces tipo lisa cultivadas sob diferentes ambientes. Revista Ciência Agronômica, 44:133-140

Embrapa - Empresa Brasileira de Pesquisa Agropécuaria (2003) Alface: produção em cultivo protegido. Brasília, Engenharia de Agricultura. p.21-26.

Feltrim AL, Filho ABC, Branco RBF, Barbosa JC \& Salatiel LT (2005) Produção de alface americana em solo e em hidroponia, no inverno e verão, em Jaboticabal, SP. Revista brasileira engenharia agrícola ambiental, 9:505-509.

Ferreira DF (2011) Sisvar: a computer statistical analysis system. Ciência agrotecnologia, 35:1039-1042.

Figueiredo EB, Malheiros EB \& Braz LT (2004) Interação genótipo $\mathrm{x}$ ambiente em cultivares de alface na região de Jaboticabal. Horticultura Brasileira, 22:66-71.

Gondim ARO, Puiatti M, Ventrella MC \& Cecon PR (2008) Plasticidade anatômica da folha de taro cultivado sob diferentes condições de sombreamento. Bragantia, 67:1037-1045.

Grangeiro LC, Costa KR, Medeiros MA, Salviano AM, Negreiros MZ, Neto FB \& Oliveira SL (2006) Acúmulo de nutrientes por três cultivares de alface cultivadas em condições do Semi-Árido. Horticultura Brasileira, 24:190-194

Gualberto R, Oliveira PSR \& Guimarães SAM (2002) Adaptabilidade e estabilidade fenotípica de diversas cultivares de alface do grupo crespa, em cultivo hidropônico. In: $42^{\circ}$ Congresso Brasileiro de Olericultura, Brasília. Anais, ABH. CD-ROM.

Guimarães MA, Mandelli MS \& Silva DJH (2011) Seleção de genótipos de Lactuca sativa $\mathrm{L}$. para a produção com adubação orgânica. Revista Ceres, 58:202-207.
Gomes TM, Botrel TA, Modolo VA \& Oliveira RF (2005) Aplicação de $\mathrm{CO}_{2}$ via água de irrigação na cultura da alface. Horticultura Brasileira, 23:316-319.

Knott JE (1962) Handbook for vegetable growers. 2a ed. New York, John Wiley e Sons. 245p.

Luz AO, Júnior SS, Souza SBS \& Nascimento AS (2009) Resistência ao pendoamento de genótipos de alface em ambientes de cultivo. Agrarian, 2:71-82.

Milthorpe FL \& Moorby J (1974) An introduction to crop physiology. Cambridge, Cambridge University. 201p.

Puiatti M \& Finger FL (2005) Fatores climáticos. In: Paulo CRF (Ed.) Olericultura - teoria e prática. Rio Branco, Suprema Gráfica e Editora. p.17-38.

Pedó T, Lopes NF, Moraes DM, Aumonde TZ \& Sacarro EL (2010) Crescimento de três cultivares de rabanete (Raphanus sativus) ao longo da ontogenia das plantas. Tecnologia \& Ciência Agropecuária, 4:17-21.

Pisco RR \& Arenas MIP (2006) Evaluacion del potencial de los biosólidos procedentes del tratamiento de aguas residuales para uso agrícola y su efecto sobre el cultivo de rabano rojo (Raphanus Sativus L.). Revista Facultad Nacional de Agronomía, 59:35433556 .

Queiroga RCF, Neto FB, Negreiros MZ, Oliveira AP \& Azevedo CMSB (2001) Produção de alface em função de cultivares e tipos de tela de sombreamento nas condições de Mossoró. Horticultura Brasileira, 19:324-328.

Santana CTC, Santi A, Dallacort R \& Santos ML (2012) Desempenho de cultivares de alface americana em respostas a diferentes doses de torta de filtro. Revista Ciência Agronômica, 43:2229.

Santi A, Carvalho MAC, Campos OR, Silva AF, Almeida JL \& Monteiro S (2010) Ação de material orgânico sobre a produção e características comerciais de cultivares de alface. Horticultura Brasileira, 28:87-90.

Santos CL, Junior SS, Lalla JG, Theodoro VCA \& Nespoli A (2009) Desempenho de cultivares de alface tipo crespa sob altas temperaturas em Cáceres-MT. Agrarian, 2:87-98.

Taiz L \& Zeiger E (2009) Fisiologia vegetal, 4 ${ }^{\mathrm{a}}$ ed. Porto Alegre, Artmed. 719p.

Viana TVA, Vasconcelos DV, Azevedo BM \& Souza VF (2002) Estudo da aptidão agroclimática do Estado do Piauí para o cultivo da aceroleira. Ciência Agronômica, 33:5-12.

Yuri JE, Souza RJ, Freitas SAC, Júnior JCR \& Mota JH (2002) Comportamento de cultivares de alface tipo americana em Boa Esperança. Horticultura Brasileira, 20:229-232.

Yuri JE, Souza RJ, Resende GM \& Mota JH (2005) Comportamento de cultivares de alface americana em Santo Antônio do Amparo. Horticultura Brasileira, 23:870-874. 